
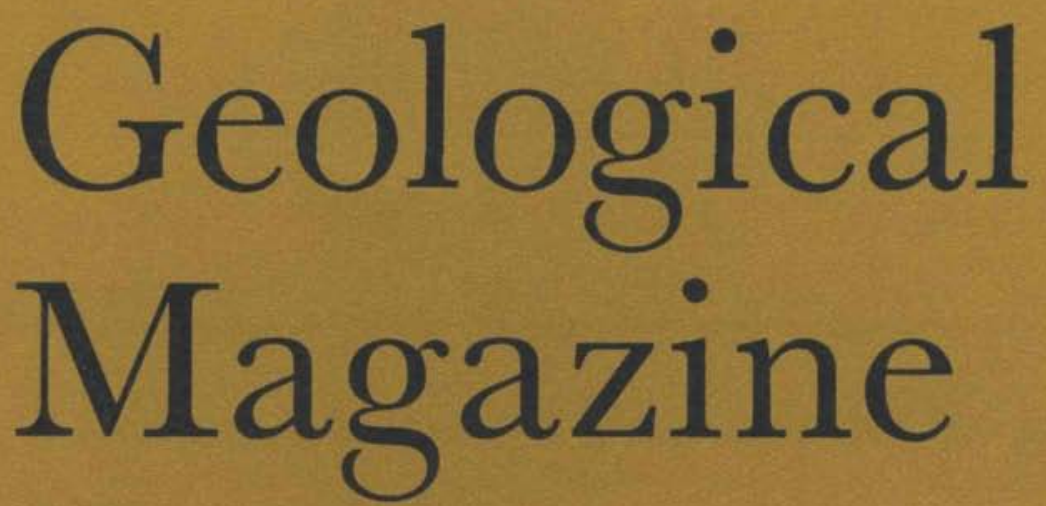

\title{
Volume 109 Number 3
}

May $197^{2}$

\section{GAMBRIDGE UNIVERSITY PRESS}




\section{Geological Magazine}

(founded in 1864, incorporating The Geologist, founded in 1858$)$.

Editors: O.M.B. Bulman, S.R. Nockolds, W.B. Harland Assistant Editor: Mrs M.J. Mason

Associate Editors: K.G. Dunham, N.L. Falcon, Leonard Hawkes, Sir William Pugh, F.W. Shotton, Sir James Stubblefield, G.E. Tilley

The Geological Magazine was originally established in 1864 and has been published continuously ever since.

It covers the whole field of earth sciences and welcomes papers which, provided they are of scientific merit, are also controversial in nature. It is the policy of the editors to encourage short papers so that all readers can expect to find at least one major item of interest in each part.

A section is devoted to scientific correspondence. Book reviews are of two kinds: essay reviews either review a group of books on related subjects or enable an author to discuss a particular topic in relation to the account given in a recently published book; in addition there are shorter reviews of recent books. The list of publications received provides a useful check list which is used by many librarians.

The editors wish it to be known that authors alone are responsible for the correctness of their references.

(c) Cambridge University Press, 1972

Permissions For permission to reproduce material from Geological Magazine, please apply to the London or New York Office of Cambridge University Press.

Geological Magazine is published every two months in January, March, May, July, September and November. Six parts form a volume.

Subscriptions should be sent to any bookseller or subscription agent, or direct to Cambridge University Press, P.O. Box 92, London N.w.I. Subscriptions in the USA or Canada should be sent to Cambridge University Press, 32 East 57th Street, New York, N.y. I0022. The subscription price is $£ 8.00$ net $(\$ 24.00$ in the USA) including postage; separate parts cost $£ 2.00$ net ( $\$ 6.00$ in the USA) plus postage. Second class postage paid at New York, N.Y.

Claims for missing issues can only be considered if made immediately after receipt of the subsequent issue.

Back Volumes Enquiries about the availability and price of back issues should be sent to Cambridge University Press.

Advertising Details of advertising in Geological Magazine may be ob-

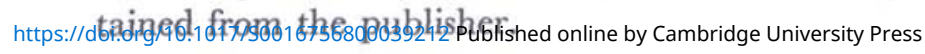

